\title{
Toxoplasma Chinese 1 Strain of WH3srop16//III/gra15 II Genetic Background Contributes to Abnormal Pregnant Outcomes in Murine Model
}

\author{
Cong Wang ${ }^{1 \dagger}$, Weisheng Cheng ${ }^{2 \dagger}$, Qian Yu', Tian Xing ${ }^{1}$, Shoubin Chen ${ }^{1}$, Lei Liu ${ }^{1}$, Li Yu', \\ Jian Du', Qingli Luo', Jilong Shen ${ }^{1,3 *}$ and Yuanhong $X u^{1,3 *}$

\begin{abstract}
'Department of Pathogen Biology, Provincial Laboratories of Pathogen Biology and Zoonoses, School of Basic Medicine, Anhui Medical University, Hefei, China, ${ }^{2}$ Department of Medical Genetics, Zhongshan School of Medicine, Sun Yat-sen University, The Key Laboratory of Tropical Disease Control, Ministry of Education, Guangzhou, China, ${ }^{3}$ Department of Clinical
\end{abstract} \\ Laboratory, The First Affiliated Hospital of Anhui Medical University, Hefei, China
}

\section{OPEN ACCESS}

Edited by:

Zhiguang Wu,

University of Edinburgh,

United Kingdom

Reviewed by:

Dolores Correa,

Instituto Nacional de

Pediatria, Mexico

Hong-Juan Peng,

Southern Medical University, China

Yong Wang,

Nanjing Medical University, China

${ }^{*}$ Correspondence:

Jilong Shen

shenjilong53@126.com;

Yuanhong Xu

xyhong1964@163.com

tThese authors have contributed equally to this work.

Specialty section:

This article was submitted to Microbial Immunology,

a section of the journal

Frontiers in Immunology

Received: 24 January 2018

Accepted: 15 May 2018

Published: 01 June 2018

Citation:

Wang C, Cheng W, Yu Q, Xing T,

Chen S, Liu L, Yu L, Du J, Luo Q,

Shen J and Xu Y (2018) Toxoplasma

Chinese 1 Strain of WH3Arop

16./II/gra15 II Genetic Background Contributes to Abnormal Pregnant

Outcomes in Murine Model.

Front. Immunol. 9:1222.

doi: 10.3389/fimmu.2018.01222
Toxoplasma gondii infection evokes a strong Th1-type response with interleukin (IL)-12 and interferon (IFN)- $\gamma$ secretion. Recent studies suggest that the infection of pregnant mice with T. gondii may lead to adverse pregnancy results caused by subversion of physiological immune tolerance at maternofetal interface rather than direct invasion of the parasite. Genotype-associated dense granule protein GRA15 || tends to induce classically activated macrophage (M1) differentiation and subsequently activating NK, Th1, and Th17 cells whereas rhoptry protein ROP16 $6_{|/|}$drives macrophages to alternatively activated macrophage (M2) polarization and elicits Th2 immune response. Unlike the archetypal strains of types I, II, and III, type Chinese 1 strains possess both GRA15 II and ROP16/III, suggesting a distinct pathogenesis of Toxoplasma-involved adverse pregnancies. We constructed T. gondii type Chinese 1 strain of WH3 3 rop16 based on CRISPR/Cas9 technology to explore the ROP16 ${ }_{\mid / \|}$-deficient/GRA15 -dominant parasites in induction of trophoblast apoptosis in vitro and abnormal pregnant outcomes of mice in vivo. Our study showed that Toxoplasma WH3 $\mathrm{Wrop} 16$ remarkably induced apoptosis of trophoblasts. C57BL/6 pregnant mice injected with the tachyzoites of WH3 $\Delta$ rop16 presented increased absorptivity of fetuses in comparison with the mice infected with $\mathrm{WH} 3$ wild type (WH3 WT) parasites although no remarkable difference of virulence to mice was seen between the two strains. Additionally, the mice inoculated with WH3Arop16 tachyzoites exhibited a notable expression of both IL-17A and IFN- $\gamma$, while the percentage of CD4+CD25+FoxP3 [T regulatory cells (Tregs)] were diminished in splenocytes and placenta tissues compared to those infected with WH3 WT parasites. Accordingly, expressions of IL-4, IL-10, and transforming growth factor beta 1, the pivotal cytokines of Th2 and Tregs response, were significantly dampened whereas IFN- $\gamma$ and IL-12 expressions were upregulated in WH3 3 rop 16-infected mice, which gave rise to more prominent outcomes of abnormal pregnancies. Our results indicated that the WH3 3 rop 16 parasites with gra $15_{\text {II }}$ background of $T$. gondii type Chinese 1 strains may cause miscarriage and stillbirth due to subversion of the maternal immune tolerance and system immunity of the animals and the GRA15 ॥ effector contributes to the process of adverse pregnant consequences.

Keywords: Toxoplasma gondii, dense granule protein GRA15, rhoptry protein ROP16, CRISPR/Cas9, adverse pregnant outcome 


\section{INTRODUCTION}

During normal pregnancy, allogeneic fetal cells invading the extraembryonic trophoblasts do not impair gestation by establishing tolerance at the maternal-fetal interface $(1,2)$. The physiological balance of Th1/Th2 is believed to play a crucial part in maintenance of normal pregnancy of mammals including humans (3). Previous studies showed that apoptosis is a normal physiological process of trophoblasts throughout gestation and is essential to normal placental development and fetal growth (4). Thus any unfavorable impact of immunological factors on the maternal-fetal interface and/or apoptosis of trophoblasts may lead to abnormal pregnancy outcomes.

It has been elucidated that $\mathrm{T}$ regulatory cells (Tregs) promote immune tolerance and successful pregnancy by secreting interleukin (IL)-10 and transforming growth factor beta 1 (TGF- $\beta 1$ ) and dampen interferon (IFN)- $\gamma$ and other inflammatory cytokines to maintain the normal development of embryos (5-8). The Tregs cells have been found to be insufficient in patients who experienced recurrent spontaneous abortions (9), while excessive secretion of IFN- $\gamma$ and other Th1 type cytokines may give rise to adverse pregnancies (10). Therefore, Th2-dominant response in system immunity and at maternal-fetal interface is the prerequisite for normal pregnancy $(3,11-14)$.

Toxoplasma gondii is an extensive intracellular protozoan parasite that is capable of affecting almost all vertebrate animals including humans and leading to reproductive failure in its hosts $(15,16)$. Primary infection with Toxoplasma during pregnancy, particularly in the first trimester, may cause stillbirths, miscarriages, or fetal abnormalities (17). The apoptosis of trophoblasts might be induced by many stimuli. For example, apoptotic process of trophoblasts is notably increased in the case of spontaneous abortion when the cells were co-cultured with inflammatory macrophages that were infected with T. gondii (18). Glycosyl phosphatidylinositol on the membrane of Toxoplasma tachyzoites, similar to LPS of bacteria, could induce oxidative stress in several tissues, and it has been found to be a key molecule which is responsible for preterm labor in mice $(19,20)$. Despite the fact that Toxoplasma infection may cause abortion or congenital fetal infection via direct transmission of parasite to placentas and fetuses, some studies indicate that imbalance of immune tolerance at the maternal-fetal interface, rather than a direct action of the parasite, might be attributed to the abnormal pregnancies $(21,22)$, resulting in apoptosis of trophoblasts in the case of abortion with T. gondii infection. Further researches revealed that Toxoplasma infection in mice lead to adverse pregnant results with a mechanism of reduction of Tregs and elevation of Th17 cells (23).

Toxoplasma gondii invasion to the host cell is actually a series of parasite protein secretions. Secretory proteins of ROPs, GRAs, MICs, RONs, and other molecules are mainly generated by the organelles of dense granules, rhoptries, and micronemes. These parasite-derived polymorphic effectors are deeply involved in dictation of virulence and modulation of host signaling pathways (24-28). For instance, Jensen et al. found that ROP16/IIII (of types I and III strains) kinase phosphorylates Stat6/Stat3 and induces alternatively activated macrophages (M2) at early phase of infection that is associated with promoted IL-4 and IL-10 expressions and Th2-polarized response, while GRA15 II (of type II strains) activates NF- $\mathrm{kB}$ and elicits classically activated macrophages (M1) that is responsible for IL-12 generation and Th1dominant immunity, subsequently activating NK and Th17 cells $(19,28-31)$, resulting in oxidative stress and further activation of the pro-apoptotic pathway $(28,32)$.

Studies reported that type Chinese 1 (ToxoDB \#9) strains dominantly prevalent in China carry both GRA15 ${ }_{\text {II }}$ and ROP16/IIII effectors that is different from the strains of archetypical types I, II, and III of T. gondii in Europe and North America $(33,34)$. The ROP16 $6_{\text {IIIII }}$ with GRA15 II background in Chinese 1 strains strongly suggests the distinct pathogenesis that differs from the strains of the other continents of the world. In the current study, we explored the impact of GRA15 II with ROP16 I/III deletion of Chinese $1 \mathrm{WH} 3$ strain parasite on adverse pregnancy outcomes in murine model by making a T. gondii WH3 3 rop 16 strain based on CRISPR/Cas9 technology. We hypothesize that the ToxoWH3 3 rop 16 strain with gra $15_{\text {II }}$ background, similar to type II strains of Toxoplasma, might subvert the immune tolerance at the maternal-fetal interface and the systemic immunity, leading to adverse pregnancy, which is attributed to the M1/Th1/Th17 biased response. Moreover, this study would be helpful for better understanding of the genotype-associated mechanism of abnormal pregnancy caused by Toxoplasma predominantly circulating in China.

\section{MATERIALS AND METHODS}

\section{Reagents}

The following reagents were used in the experiment: Q5 mutagenesis kit (New England Biolabs, Ipswich, MA, USA) and ClonExpress MultiS One Step Cloning Kit (Vazyme Biotech, Nanjing, China). Phusion High-Fidelity PCR Kit (Thermo fisher, USA) was used for the PCR amplification. Percoll (GE Healthcare Life Sciences), pyrimethamine, penicillin, streptomycin, phorbol 12-myristate 13-acetate, ionomycin, HEPES, collagenase IV, and the Giemsa staining kit, were obtained from Sigma (St. Louis, MO, USA). Dulbecco's modified Eagle's medium, fetal bovine serum (FBS), and Roswell Park Memorial Institute 1640 medium (RPMI 1640) and D-Hanks solution were purchased from Wisent (Montreal, QC, Canada). Brefeldin A, FITC-labeled anti-mouse CD4, PE-labeled anti-mouse IL-17A, APC-labeled anti-mouse IL-4, Percp-cy5.5-labeled anti-mouse IFN- $\gamma$, APC-labeled antimouse CD25, PE-labeled anti-mouse Foxp3, FITC Annexin V Apoptosis Detection Kit, and Cytofix/Cytoperm kit were provided by BD Biosciences (New York, BD, USA). The nitrite was detected via Greiss Reagent System provided by Promega Biotech Company (Madison, WI, USA). The tumor necrosis factor (TNF- $\alpha$ ), IL-17A enzyme-linked immunosorbent assay (ELISA) kit, and $1 \times$ Fix/Perm buffer were purchased from eBioscience (San Diego CA, USA). IFN- $\gamma$, IL-12, IL-10, and TGF- $\beta 1$ ELISA kit was obtained from R\&D Systems (Minneapolis, MN, USA). The mouse trophoblasts (primary cells originated from C57BL/6 mice) were purchased from Wuhan Biofavor Biotechnology Company. 


\section{Propagation of T. gondii}

Tachyzoites of T. gondii WH3 strain (type Chinese 1) were harvested from the continuous cell cultures in human foreskin fibroblasts (HFF, ATCC ${ }^{\circledR}$ SCRC-1041 ${ }^{\mathrm{TM}}$ ) grown with Dulbecco's modified Eagle medium (DMEM) supplemented with 10\% FBS, $100 \mu \mathrm{g} / \mathrm{ml}$ streptomycin, and $100 \mathrm{U} / \mathrm{ml}$ penicillin.

\section{Generation of ROP16 ${ }_{1 / I I I}$-Deficient Strain of Type Chinese 1}

All the primers and plasmids used in the study are shown in Table 1. UPRT-targeting guide RNA (gRNA) in pSAG1:CAS9U6:sgUPRT (Addgene plasmid \#54467) was replaced with ROP16 $6_{\text {IIII }}$ targeting gRNA using Q5 mutagenesis kit. To make the homologous templates for gene replacements, homologous arms of ROP16 $6_{\text {I/III }}$ were amplified from the genomic DNA of type Chinese $1 \mathrm{WH} 3 \mathrm{WT}$ strain as described in previous study (35). Subsequently, the homologous arms of ROP16 along with the selectable markers DHFR ${ }^{\star}$-Ts were cloned into pUC19 using ClonExpress MultiS One Step Cloning Kit. The pSAG1:Cas9U6:sgROP16 $6_{\mathrm{I} / \mathrm{III}}$ and donor DNA fragments were electroporated into T. gondii WH3 WT strain. After transfection, tachyzoites were immediately transferred into HFF cells. After culture for $48 \mathrm{~h}$, parasites were selected with pyrimethamine for DHFR-TS. A single clone through limiting dilution in 96-well plate were seeded with HFF host cells and detected by PCR and Western blotting. Diagnostic PCRs (PCR1, PCR2, and PCR3) were used to screen individual clone. PCR reactions were performed using Taq DNA polymerase in a $25-\mu$ l reaction mixture containing $1 \mu \mathrm{l}$ genomic DNA extracted from a single clone as templates. Subsequently, the products were examined by agarose gel electrophoresis. Rabbit polyclonal antibody against ROP18 and antibody against ROP16 was prepared in the laboratory. The invasion of WH3 WT or WH3 3 rop 16 strain in HFF cells were visualized after $48 \mathrm{~h}$ by Giemsa staining and the average number of tachyzoites per parasitophorous vacuole (PV) was obtained by counting $50 \mathrm{PVs}$ in triplicate experiments. C57BL/6 mice were infected with $1 \times 10^{3}$ tachyzoites of WH3 WT or WH3 3 rop 16 , respectively. The animals were monitored daily for manifestations following infection and the survival rate was recorded.

\section{Cells and Co-Culture System}

Mouse peritoneal macrophages were acquired by washing the peritoneal cavity three times with ice-cold D-Hanks solution. Mouse peritoneal macrophages were cultured and suspension cells were washed off $24 \mathrm{~h}$ later. The transwell culture plates (Corning, Corning, NY, USA), were used to establish a coculture system. Generally, the pore size of the bottom of the inserts is $0.4 \mu \mathrm{m}$, which allowed the passage of only small and soluble particles rather than cells and tachyzoites. Control macrophages $\left(1 \times 10^{6}\right)$ and WH3 WT $\left(1 \times 10^{6}\right)$ or WH3 3 rop 16 $\left(1 \times 10^{6}\right)$ tachyzoites infected macrophages were added to the upper well separately. The $\mathrm{C} 57 \mathrm{BL} / 6$ primary placental trophoblasts $\left(1 \times 10^{6}\right)$ were co-cultured in the lower wells in $5 \% \mathrm{CO}_{2}$ at $37^{\circ} \mathrm{C}$ for $24 \mathrm{~h}$. The co-culture system was kept in $1 \mathrm{ml}$ of RPMI 1640 culture medium supplemented with 10\% FBS and $1 \%$ penicillin/streptomycin. After co-culturing for $24 \mathrm{~h}$, the macrophages were harvested for total RNA and culture supernatants were collected to analyze NO and TNF- $\alpha$. The placental trophoblasts were collected for detection of apoptosis by flow cytometry (FCM). The apoptosis rates of trophoblasts cells were calculated as the sum of early and late apoptosis rates. The trophoblasts cells washed twice with cold PBS, and resuspended cells in $1 \times$ binding buffer. The trophoblast cells were subjected to FITC annexin V and PI followed by gentle vortex, incubated for $15 \mathrm{~min}$ at $25^{\circ} \mathrm{C}$ in the dark and analyzed by FCM within $1 \mathrm{~h}$.

\section{Establishment of Animal Pregnant Model}

The 6- to 8-week-old female and 8- to 10-week-old male C57BL/6 mice were purchased from the Animal Center of Anhui Medical University (AMU) and had free access to sterilized water and food under standard conditions, and permitted to adapt for 1 week before the experiment. The mice were treated in compliance with the Chinese National Institute of Health Guide for the Care and Use of Laboratory Animals.

TABLE 1 | Primers used in this study.

\begin{tabular}{lll}
\hline Primers & Sequence & Used for \\
\hline 5'-ROP16-guide RNA (gRNA) & GTGGCAGCGCGTTTAGAGCTAGAAATAGCAAG & Q5 mutagenesis changing the gRNA in \\
3'-ROP16-gRNA & CGGTGCGTCCAACTTGACATCCCCATTAC & pSAGAS9-U6:sgUPRT to gRNA-ROP16 \\
\hline UpROP16 F & AAAACGACGGCCAGTGAATCAGTTGAATCTCTGGGTAGAACAGC & To produce UpROP16 PCR product for \\
UpROP16 R & GGGGGTGAAATCGAATGACACTGCCCCTGAGTCGAGCCAC & To produce DHFR PCR product for \\
\hline DHFR-TS F & TGTCATTCGATITCACCCCC & making pROP16:DHFR-I \\
DHFR-TS R & TCCTCCGCTCCTCTCTAGCAGGATCGATCCCCCCGGGCTGC & To produce DnROP16 PCR product for \\
\hline DnROP16 F & GCAGCCCGGGGGGATCGATCCTGCTAGAGAGGAGCGGAGGA & making pROP16:DHFR-I \\
DnROP16 R & GACCATGATTACGCCAAGCTTGCTCCGCAGTCTCTGTAAGT & PCR1 \\
\hline 5'-UpROP16 & TGTGATGCTGAGTCTTGCGAGT & PCR2 \\
\hline 5'-InDHFR & TACCAGTCATGGACGAGATCG & PCR3 \\
\hline 3'-InDHFR & ACACGCATGTCTACACGAACC & \\
3'-DnROP16 & TGGTGGTTGCGACTGGACTA & \\
\hline 5'-InROP16 & ATGAAAGGACCACGAAAGG & \\
3'-InROP16 & CTACATCCGATGTGAGAAAGT &
\end{tabular}


All procedures were followed strictly according to the ethical standards formulated by Institutional Review Board of AMU Institute of Biomedicine AMU (permit No: AMU26-081108). After 1 week of adaptation to the new environment, females were housed overnight with males ( 2 females for 1 male). The presence of vaginal plugs on the second day was designated day 0 of gestation (GD 0). Briefly, all pregnant mice were divided into three equal groups randomly (WH3 WT group, WH3 3 rop 16 group, and control group) with five mice in each. On gestation GD8, pregnant mice were intraperitoneally injected with $4 \times 10^{2} \mathrm{WH} 3 \mathrm{WT}$ and WH3 3 rop 16 tachyzoites in $200 \mu \mathrm{l}$ sterile PBS, and the control was exposed to only $200 \mu \mathrm{l}$ sterile PBS at the same time. All mice were sacrificed with euthanasia on GD14, the uteruses were moved away and implantation and resorption sites were recorded. The resorption sites were defined by their small sizes, necrotic, and hemorrhagic appearance of placentas and embryos. The ratio of resorption sites to total implantation sites was calculated as the percentage of fetal loss.

The experiments that are related to using viable parasites and animal infections were performed in the AMU Biosecurity II Laboratory licensed by the local health administrative department.

\section{Preparation of Single Cell Suspension}

The placentas, uterine tissues, and spleens of experimental mice were removed aseptically. The spleen tissues were placed in a sterile nylon mesh gently. The cells were harvested after mashing through sterile nylon gauze and lysed with erythrocyte lytic buffer and cultured in RPMI 1640 supplemented with 10\% FBS. At the same time, the placentas and the uterus were placed in the dish and cut into pieces followed by washing thoroughly and the shredded tissue was moved to a $50 \mathrm{ml}$ centrifuge tube. The tissues digested with $2.5 \mathrm{mg} / \mathrm{ml}$ collagenase IV, 10\% FBS, and $10 \mathrm{mM}$ HEPES sodium salt dissolved in RPMI 1640 and then incubated at $37^{\circ} \mathrm{C}$ for $30 \mathrm{~min}$ with gentle shaking. The suspension cells were filtered through sterile nylon mesh to take away undigested tissue. The mononuclear cells were collected by discontinuous 70\%/40\% Percoll (GE Healthcare Life Sciences) density gradient centrifugation.

\section{FCM Analysis of Lymphocytes}

Lymphocytes from spleens, placentas, and uterine tissues were regulated to the appropriate cell number $\left(1 \times 10^{6} / \mathrm{ml}\right)$ and cultivated in 6-well plate in $2 \mathrm{ml}$ of RPMI 1640 medium supplemented with $10 \%$ FBS. For intracellular cytokine staining, ionomycin $(1 \mathrm{mg} / \mathrm{ml})$ and PMA $(20 \mathrm{ng} / \mathrm{ml})$ were used to stimulate the cells for $5 \mathrm{~h}$ in the presence of brefeldin A $(1 \mathrm{mg} / \mathrm{ml})$. The cells were subjected to FITC-labeled anti-mouse CD4 for $30 \mathrm{~min}$ at $4^{\circ} \mathrm{C}$ to avoid the light and were washed twice, and fixed with the Cytofix/ Cytoperm kit according to manufacturer's instructions. The cells were incubated for $1 \mathrm{~h}$ at $4^{\circ} \mathrm{C}$ in the dark and were washed twice, and PE-labeled anti-mouse IL-17A, APC-labeled anti-mouse IL-4, and Percp-cy5.5-labeled anti-mouse IFN- $\gamma$ were used for staining of intracellular cytokines, respectively. Tregs were marked by the FITC-labeled anti-mouse CD4 and APC-labeled anti-mouse $\mathrm{CD} 25$ for $30 \mathrm{~min}$ at $4^{\circ} \mathrm{C}$ in the dark and were washed twice. After surface staining, the cells were fixed and permeabilized in $1 \times$ Fix/Perm buffer at $4^{\circ} \mathrm{C}$ for $1 \mathrm{~h}$ in the dark and washed twice, followed by PE-labeled anti-mouse Foxp3 staining at $4^{\circ} \mathrm{C}$ for $30 \mathrm{~min}$ in protection from light. After washing, the cells were analyzed on FCM.

\section{RNA Extraction and qRT-PCR}

Total RNA from the co-cultured cells, spleens, and placentas were extracted using TRIzol (Invitrogen Life Technologies, Carlsbad, CA, USA) and transcribed into cDNA using Takara Kit (Takara, Japan) following the manufacturer's instructions. The quantitative analysis was performed by testing expression of iNOS, TNF- $\alpha$, IFN- $\gamma$, IL-12, IL-17A, IL-10, and TGF- $\beta 1$ using SYBR Premix Ex Taq kit (Takara, Japan) by the Light Cycler 480. The glyceraldehyde-3-phosphate dehydrogenase (GAPDH) was used to normalize the results. The relative mRNA expression was counted with the comparative $\Delta \mathrm{Ct}$ method using the formula $2^{-\Delta \Delta C t}$. The qRT-PCR was conducted in technical triplicates by using the sense and antisense primers listed in Table 2.

\section{Enzyme-Linked Immunosorbent Assay}

The co-cultured supernatants were obtained for TNF- $\alpha$ detection by ELISA. To detect cytokines in splenocyte supernatants, we used the ionomycin $(1 \mathrm{mg} / \mathrm{ml})$ and PMA $(20 \mathrm{ng} / \mathrm{ml})$ to stimulate the splenocyte cells $\left(2 \times 10^{6}\right)$ in 6 -well plate in $2 \mathrm{ml} /$ well of RPMI 1640 medium supplemented with $10 \%$ FBS for $5 \mathrm{~h}$. Splenocyte supernatants were collected and subjected to examination for IFN- $\gamma$, IL-12, IL-17A, IL-10, and TGF- $\beta 1$ by ELISA. Accurately weighed placenta tissues were homogenized with a ratio of $1 \mathrm{mg}$ of placental tissues to $10 \mu \mathrm{l}$ of PBS and centrifuged at $12,000 \mathrm{~g}$ at $4^{\circ} \mathrm{C}$ for $30 \mathrm{~min}$. The supernatants of the tissue lysates were gathered and equal volume of the supernatants was added to each well. The cytokines of IFN- $\gamma$, IL-12, IL-17A, IL-10, and TGF- $\beta 1$ were detected by ELISA according to the manufacturer's protocols. Three duplicate wells were set up for each group. The absorbance was measured at $450 \mathrm{~nm}$ on the ELISA plate reader (Biotek, Winooski, VT, USA).

\section{Nitrite Detection}

The co-cultured supernatant was collected for examination of nitrite oxide (NO). It was detected using the Griess Reagent

TABLE 2 | The primers used for qRT-PCR.

\begin{tabular}{|c|c|c|}
\hline Primers & Forward primer $\left(5^{\prime}-3^{\prime}\right)$ & Reverse primer $\left(5^{\prime}-3^{\prime}\right)$ \\
\hline$N F-\alpha$ & ACGGCATGGATCTCAAAGAC & GTGGGTGAGGAGCACGTAGT \\
\hline NOS & CAGT & GATGC \\
\hline IFN- $\gamma$ & AGGATGC & $\mathrm{ACTG}$ \\
\hline |L-12 & & TGA \\
\hline IL-10 & GACT & हाTा \\
\hline TGF- $\beta 1$ & $\begin{array}{l}\text { CTGGATACCAACTACT } \\
\text { GCTTCAG }\end{array}$ & $\begin{array}{l}\text { TTGGTTGTAGAGGGCAAGG } \\
\text { АCCT }\end{array}$ \\
\hline & TCTCTGATGCTGTTGO & CGTGGAACGGTTGAGGTAGT \\
\hline APDH & CAACTTTGGCATTGTGGAAGG & ACACATTGGGGGTAGGAACA \\
\hline
\end{tabular}

GAPDH, glyceraldehyde-3-phosphate dehydrogenase; IFN, interferon; IL, interleukin; iNOS, inducible nitric synthase; TNF, tumor necrosis factor; TGF- $\beta 1$, transforming growth factor beta 1 . 
system as previously described (36) following the manufacturer's instruction. The absorbance was measured at $550 \mathrm{~nm}$ on an ELISA plate reader.

\section{Statistical Analysis}

The experimental data acquired were subjected to statistical analyses using one-way ANOVA and paired $t$-test after precheck of the data for homogeneity of variances. Statistical significance was defined by using GraphPad Prism Software, and $P<0.05$ was regarded as significant. The results were presented as mean $\pm S D$, which gives a summary of the data from at least three times experiments.

\section{RESULTS}

\section{The WH3دrop16 Strain of T. gondii Type Chinese 1 Was Constructed Using CRISPR/Cas9 Technology}

The CRISPR/Cas9 strategy was used to inactivate ROP16 by inserting pyrimethamine-resistant DHFR (DHFR ${ }^{\star}$ ) followed by PCR identification of a single clone (Figure 1A). PCR identification proved that DHFR coding sequence was successfully inserted to the target position (Figure 1B). Western blotting analysis showed no expression of ROP16//II protein by WH3 3 rop 16 strain (Figure 1C). Giemsa staining results indicated that less number of parasites ( 13 tachyzoites vs 22 tachyzoites) per PV in WH3 3 rop16 infected cells compared to WH3 WT-infected cells, respectively $(p<0.05)$ (Figure 1D). Virulence examination indicated that all animals infected by both strains died on day 12 post-infection (Figure 1E) and no difference of the virulence to mice was noted between WH3 WT and WH3 3 rop16 strains.

\section{WH3srop16 Strain Infection Drove Macrophages to M1 and Lead to Trophoblast Apoptosis}

Compared to the WH3 WT group, macrophages infected with WH3 3 rop 16 strain produced a higher level of NO, iNOS, and TNF- $\alpha$ (Figures 2A,B). To elucidate the placental trophoblasts apoptosis, we detected cell apoptosis of placental tissues by fluorescein isothiocyanate/propidium iodide (FITC/PI) staining assay. Compared to the WH3 WT group, the number of total, early, and late apoptotic cells of trophoblasts was elevated when co-cultured with WH3 3 rop 16 strain-infected macrophages for $24 \mathrm{~h}$ (Figure 2C). The remarkable apoptosis of trophoblasts caused by WH3 $\mathrm{Wrop} 16$ strain was observed (Figure 2D).

\section{WH3دrop16 Strain Infection Induced Adverse Pregnancy}

Most samples of the pregnant uteruses showed significant fetal resorption and placental hemorrhage in the mice
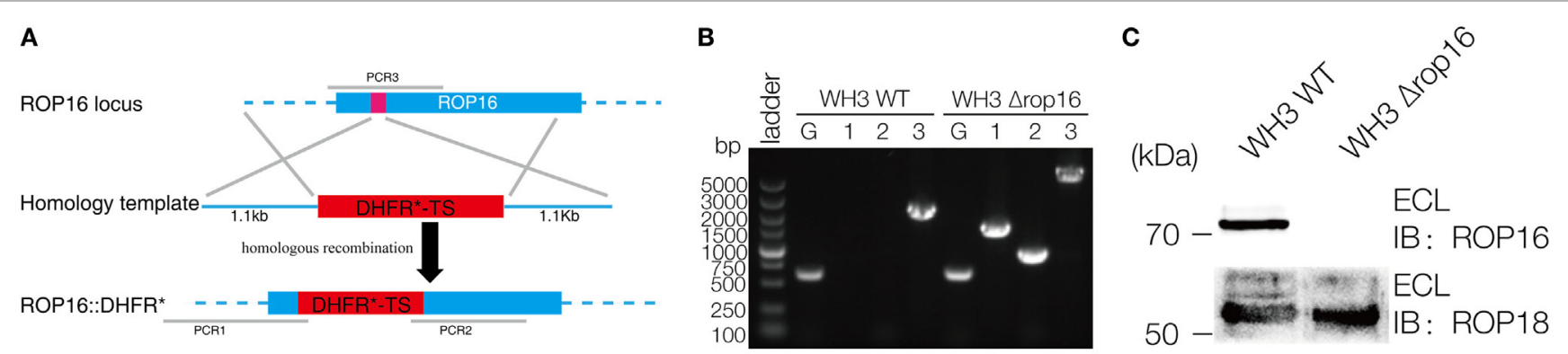

D

WH3 WT

WH3 $\Delta$ rop16

E
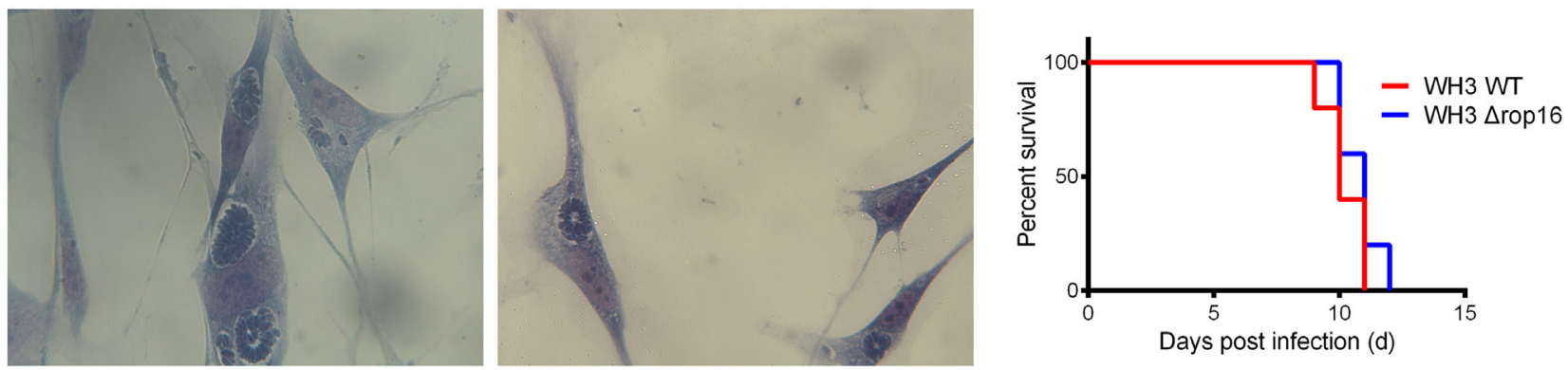

FIGURE 1 | Construction of the WH3 3 rop16 strain of Toxoplasma gondii type Chinese 1 by using CRISPR-Cas9 technology. (A) Schematic of CRISPR/CAS9 strategy for inactivation of rop16 by inserting pyrimethamine-resistant DHFR (DHFR*) and PCR identification of single clone. (B) PCR identification of WH3 $\Delta$ rop16 T. gondii strain. G represents the GRA1 promoter positive control, as shown in Figure 1A. 1: PCR1 fragment; 2: PCR2 fragment, 3: PCR3 fragment. PCR1 and PCR2 examined the integration of DHFR-TS* into corresponding genes, and PCR3 checked the deletion of ROP16 sequences. (C) Western blotting for detection of ROP16 expression in WH3 WT and WH3 3 rop16. Rabbit polyclonal antibody against ROP18 was used as the control. (D) The number of parasites per parasitophorous vacuole of WH3 3 rop 16 or WH3 WT. (E) Mouse survival after inoculation with T. gondii tachyzoites. 


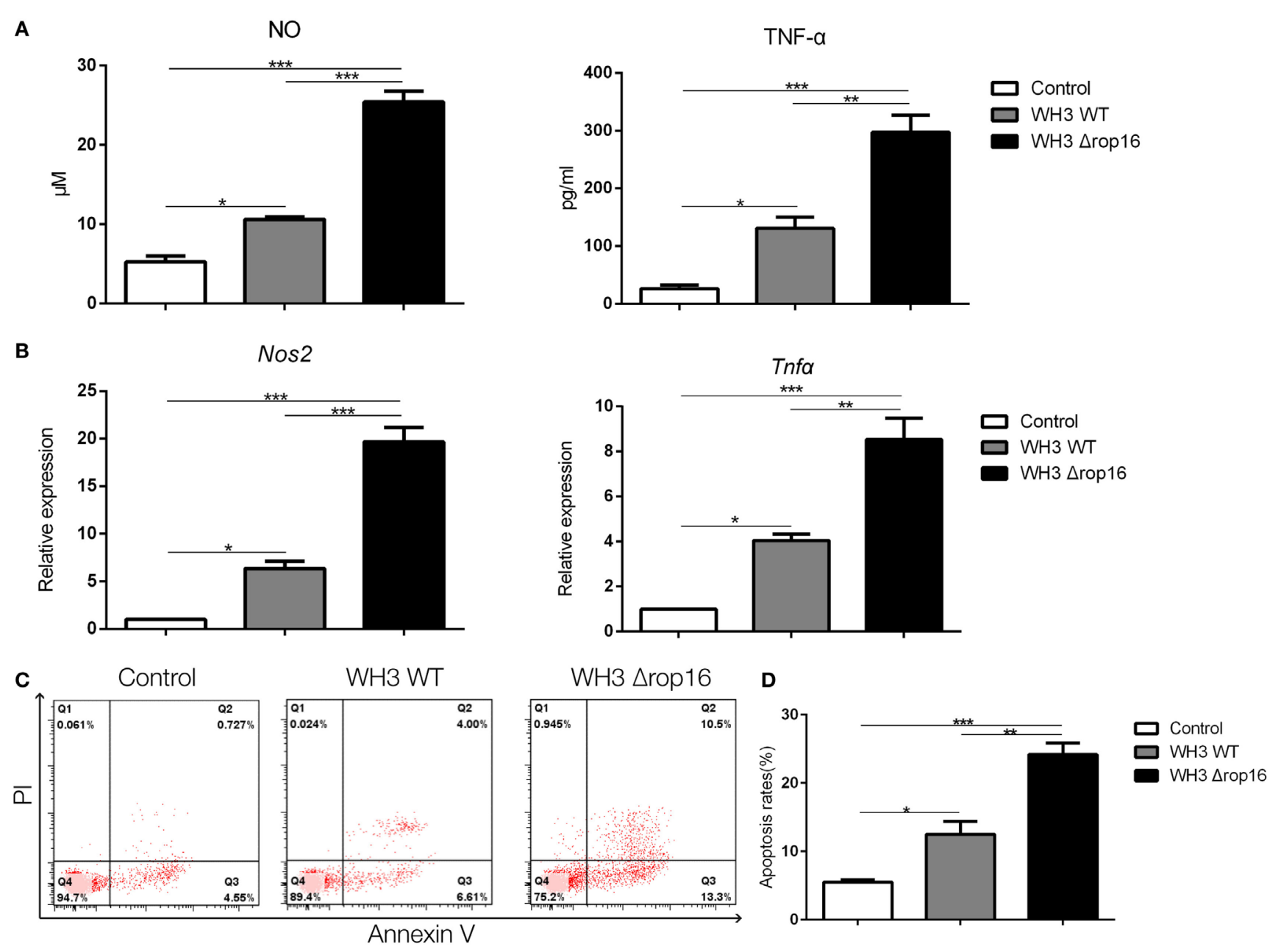

FIGURE 2 | The high production of nitrite oxide (NO), inducible nitric synthase (iNOS), and tumor necrosis factor (TNF)- $\alpha$ and apoptosis of trophoblasts co-cultured with macrophages infected with the WH3 $\Delta$ rop16 tachyzoites. (A) The culture supernatants were collected and analyzed for NO and TNF- $\alpha$ production. (B) The relative mRNA expressions of iNOS and TNF- $\alpha$ after co-culture. (C) Increased apoptosis of trophoblasts co-cultured with WH3 $\Delta$ rop16 infected macrophages.

(D) Total, early, and late apoptosis of placental trophoblasts $\left({ }^{\star} p<0.05,{ }^{\star \star} p<0.01,{ }^{\star \star \star} p<0.001\right)$.

infected with the tachyzoites of WH3 3 rop16 in comparison with the WH3 WT group (Figures $\mathbf{3 A}, \mathbf{B}$ ). The weights of fetuses, placentas, and rate of fetal loss were determined at day 6 post infection. The weight loss of fetuses and placentas was observed and the rate of fetal loss significantly increased in mice infected with WH3 3 rop 16 strain compared to WH3 WT strain (Figure 3C).

\section{WH3دrop16 Strain Infection Induced Immune Bias to Th1 in the Spleens and Placentas of Pregnant Mice}

We examined the IFN- $\gamma$ in the lymphocytes of the spleen and placenta tissues using FCM to investigate the immune bias at maternal-fetal interface of the pregnant mice after $T$. gondii infection. The expression of IFN- $\gamma$ and IL-12 were analyzed using qRT-PCR and ELISA in the spleens and placentas. Compared to WH3 WT group, Th1 subsets $\left(\mathrm{CD}^{+} \mathrm{IFN} \gamma^{+}\right)$of $\mathrm{WH} 3 \Delta$ rop16 inoculated mice were remarkably elevated (Figures 4A,B). The data were further confirmed by using qRT-PCR and ELISA (Figures 4C-F). Consistent with the IFN- $\gamma$ assay, the expression of IL-12 (Figures 4C-F) was synchronously increased in the mice of WH3 3 rop 16 infection.

\section{Th17 Response Was Upregulated in the Spleens and Placentas of the Pregnant Mice Infected With WH3srop16 Strain}

We examined the Th17 cytokine $\left(\mathrm{CD} 4^{+} \mathrm{IL}-17 \mathrm{~A}^{+}\right)$in the spleens and placentas in the three groups of mice by FCM and found that the mice infected with WH3 $\Delta$ rop16 strain exhibited a high expression of IL-17A (Figures 5A,B). The level of IL-17A mRNA expression in WH3 $\mathrm{W}$ rop16 group was significantly increased when compared to WH3 WT (Figures 5C,D), which is in parallel with the result of IL-17A detection in supernatants by ELISA (Figures 5C,D). 
A

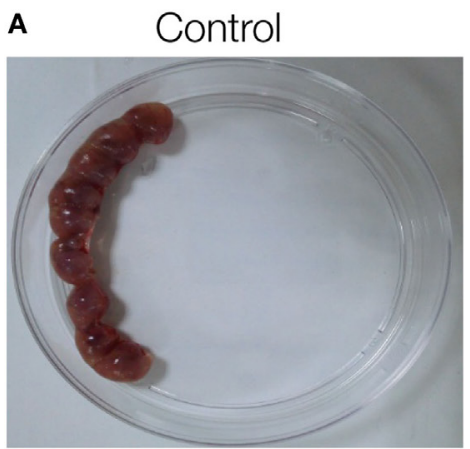

B
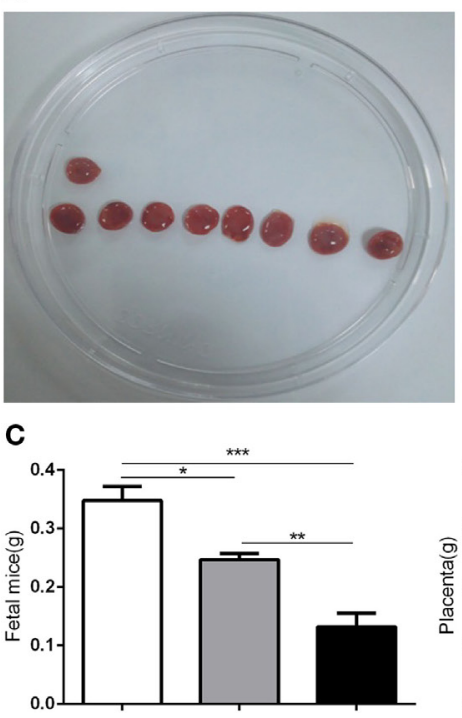
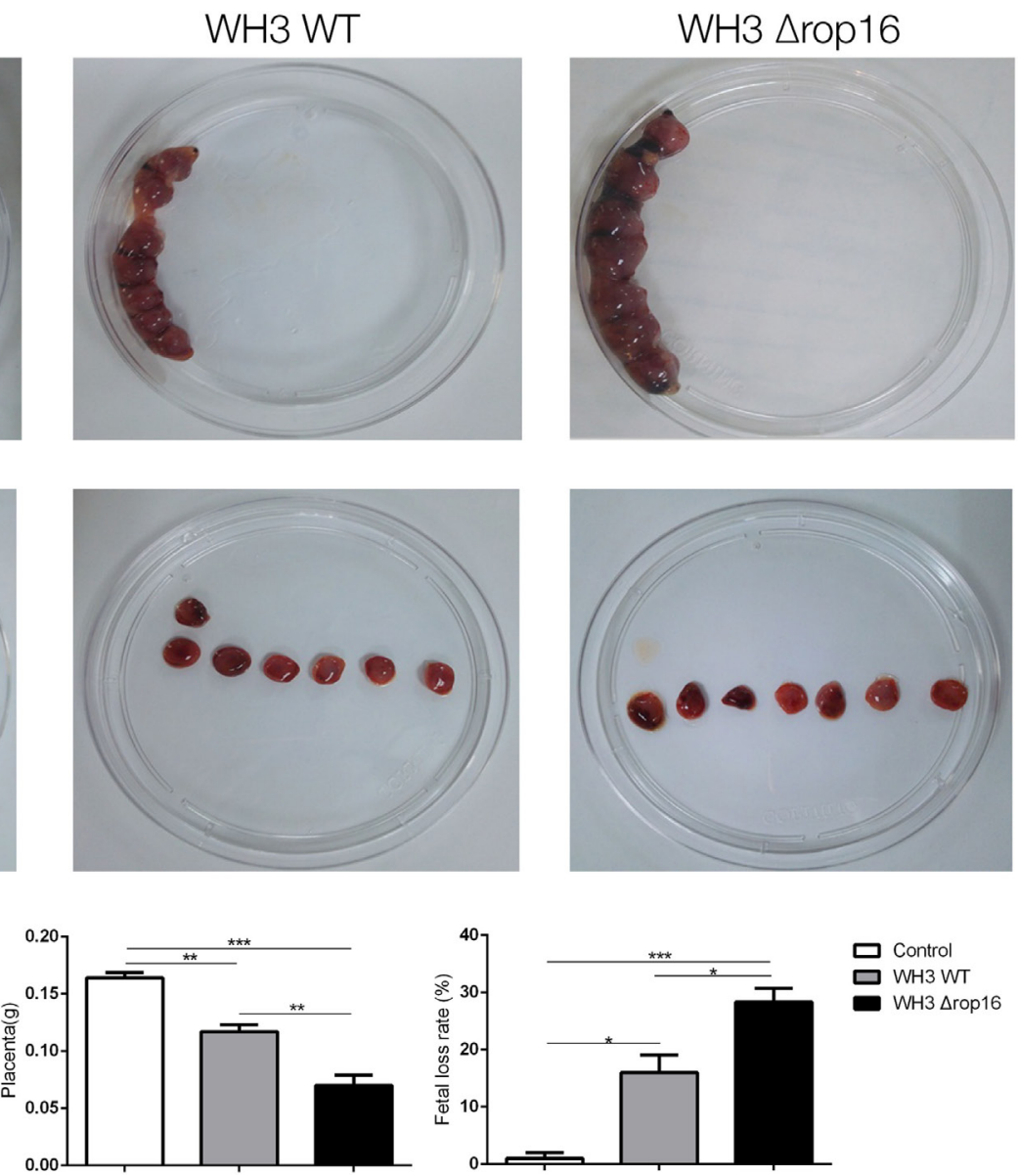

FIGURE 3 | Toxoplasma gondii infection induced adverse pregnancy outcomes in mice. (A,B) The uteruses of WH3 $\Delta$ rop16-infected mice presented notable fetal resorption and placental bleeding in comparison with the WH3 WT group. (C) The weights of fetuses, placentas, and rate of fetal loss were measured at day 6 post infection. The fetal loss rate was calculated by ratio of resorption sites to the total number of implantation sites. $\left({ }^{\star} p<0.05,{ }^{\star \star} p<0.01,{ }^{\star \star \star} p<0.001\right)$.

\section{Percentage of Tregs Decreased in the Spleens and Placentas of the Pregnant Mice Following WH3srop16 Strain Infection}

To clarify whether the mutant WH3 $\Delta$ rop16 strain infection can negatively affect the Tregs population, we detected the percentage of Tregs in the splenocytes and the cells isolated from the placentas of pregnant mice by FCM (Figures 6A,B). The results revealed that Tregs were significantly dampened in WH3 $\Delta$ rop16-infected mice. Accordingly, relative mRNA expression of IL-10 and TGF- $\beta 1$ in the spleens (Figure 6C) and placentas (Figure 6D) was synchronously reduced in WH3 3 rop 16 group compared to WH3 WT group. In addition, the levels of IL-10 and TGF- $\beta 1$ in the spleens (Figure 6E) and placentas (Figure 6F) remarkably declined in the WH3 3 rop16-infected mice when compared to WH3 WT mice.

Compared to the WH3 WT-infected C57BL/6 pregnant mice, the animals inoculated with $\mathrm{WH} 3 \Delta$ rop 16 tachyzoites presented a diminished expression of IL- 4 determined by FCM (Figures 7A,B).

\section{DISCUSSION}

Toxoplasma gondii is one of the common causative agent of prenatal infections during pregnancy $(15,16)$. The parasite may be transmitted vertically by tachyzoites that are passed to the fetus via the placenta, leading to miscarriages, stillbirths, and other adverse pregnant outcomes depending on the stage of the pregnancy at which infection takes place (37). Most strains which infect humans in Europe are type II and a large proportion of cases of congenital toxoplasmosis are asymptomatic at birth if the mother acquired the infection after the second trimester of gestation (38). It has been well recognized that vertical transmission of the parasite, particularly type I virulent strain of Toxoplasma with superior migratory capacity, may directly cause abnormal pregnancy. However, the non-virulent strains such as PRU or ME49 may induce a decrease in the fertility if infection occurs during the later phase of gestation (39). Previous studies indicated that neither parasites nor their DNAs are detectable in the diseased tissue samples of some abnormal pregnancies and we attempted to examine the parasite by bioassay or its derived DNAs by PCR from placentas and tissues of aborted fetuses in the 


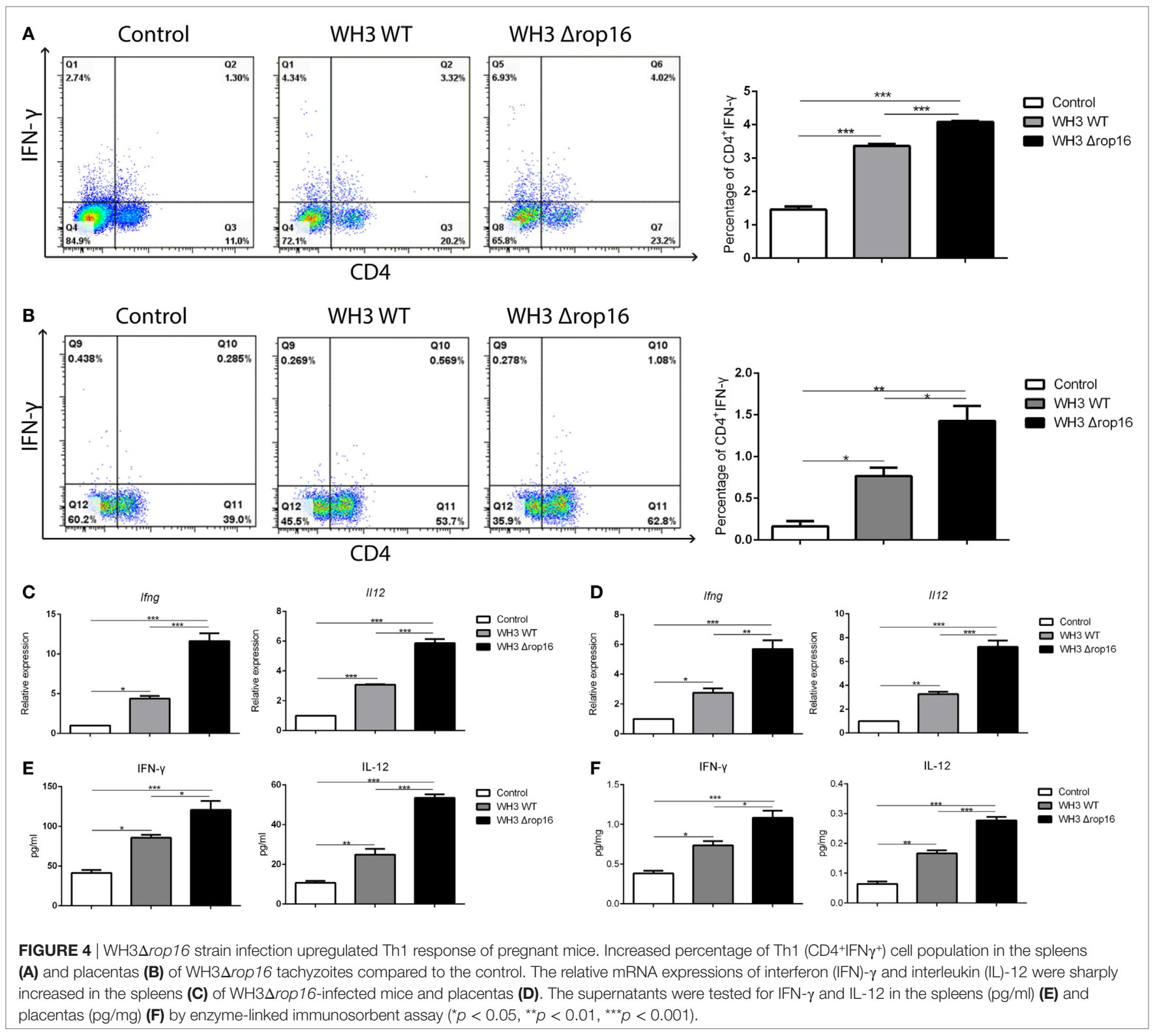

pregnant women, some of whom showing positive IgG antibodies against Toxoplasma, but no positive results were obtained (data not shown). Consistent results were also reported by Senegas in murine model (40). All of these data imply that the resorption, abortion, or fetal damage might be indirectly due to lesions of the placenta induced by maternal biased immunity such as Th1/ IFN- $\gamma$ polarized immune response (41) and that the maternal immunity-associated but not viable parasite-generated "sterile" pathology actually takes place in abnormal pregnant consequences caused by Toxoplasma infection. Herein, we focused on the maternal immunity associated rather than the mother-to-child vertical transmission causative adverse outcomes of pregnancy. Our results strongly suggest that the immunity subversionrelated pathogenesis is involved in early gestation induced by T. gondii but not due to a direct invasion of the parasite in adverse pregnancies.
It has been reported that the consequences of congenital toxoplasmosis vary in genotypes of Toxoplasma strain (42). Strains of T. gondii from Europe and North America belong to three distinct clonal lineages (type I, type II, and type III) which differ phenotypically in virulence $(43,44)$. Recent studies revealed that polarization of alternatively activated macrophage (M2) or classically activated macrophage (M1) of host macrophages depends on the polymorphism of ROP 16 or GRA 15 of Toxoplasma at early stage of infection. One site mutation of ROP16 at 503L/S would determine the activity or inactivity of ROP16 in phosphorylation of Stat6/Stat3. Type I and type III strains carry ROP16 which strongly drives M2 bias but ROP16 II is negligible $(30,45,46)$, while type II strains infected macrophages are classically activated through bypassing TLRs and directly activating NF- $\kappa \mathrm{B}$ by the dense granule protein GRA15 1 II $(28,30)$. Interestingly, we found that type Chinese 1 (ToxoDB \#9) strains carry both ROP16 I/III 


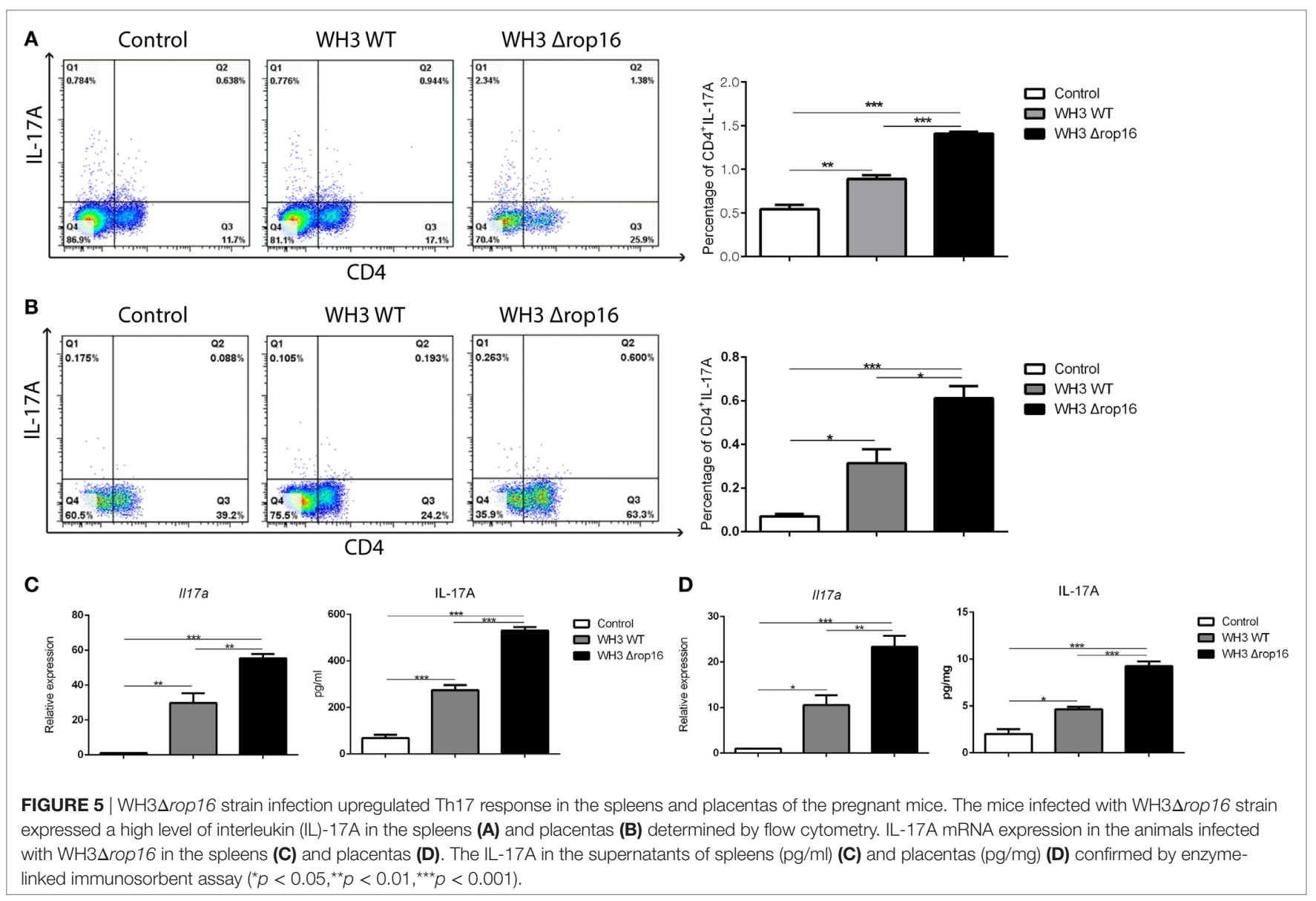

and GRA15 1 II 3 , 34). Thus, we postulated that Chinese 1 strains might have immunopathogenesis which is distinct from the archetypical strains circulating in the other parts of the world. Herewith, we constructed T. gondii WH3 3 rop16 strain based on CRISPR/Cas9 strategy. The genetically manipulated parasite WH3 strain with rop16 ${ }_{I / I I I}$-deficient and gra15 II $^{-}$dominant back-

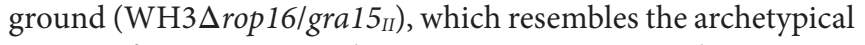
type II of European/North American strains, may be prone to induce adverse pregnant outcomes via the mechanism of subverting maternal immunotolerance. We noted that WH3 3 rop 16/ gra15 $5_{I I}$ efficiently in vitro drove macrophage polarization toward M1 cells, producing NO, TNF- $\alpha$, and iNOS, and gave rise to trophoblast cells apoptosis compared to WH3 WT strain. We also found that the WH3 3 rop $16 /$ gra $15_{\text {II }}$ strain induced characteristic Th1-biased and Th17-involved inflammatory response in vivo at maternal-fetal interface featured by high expression of IFN- $\gamma$ and IL-12, and resulted in more severe adverse pregnant consequences in murine model. These results suggest that ToxoGRA15 $5_{\text {II }}$ is one of the key factors involved in the imbalance of maternal immune tolerance during pregnancy which is associated with $\mathrm{M} 1 / \mathrm{Th} 1 / \mathrm{Th} 17$ skewed response. These results are in correspondence with the findings previously reported. Surely, in addition to GRA15 II, other Toxoplasma-derived effectors of type Chinese 1 strain may also contribute to the pathology of immunity imbalance in pregnant animals.
In the construction of the plasmids, insertion of the pyrimethamine resistance gene (dihydrofolate reductase-thymidylate synthase, DHFR-TS ${ }^{\star}$ ) has been frequently used as the selectable marker for transformant screening of CRISPR/Cas9-based genetic deletion of Toxoplasma $(35,47)$. The DHFR-TS* is not believed to evoke the detectable phenotypical alterations in Toxoplasmainfected host, since it is a modified endogenous gene that exists in wild-type strains of the parasite. So far, no evidence has shown its immunogenicity which is able to induce undesirable immune response in its host cells. Moreover, we here did not use ROP16 insertion substituting ROP16 $6_{\text {I/III }}$ because, as stated above, ROP16 I/ III, rather than ROP16 II, decides ROP16 kinase activity on Stat6/ Stat 3 and induces M2 polarization which is pivotal to M2 and subsequent Th2 response $(45,46)$. We deleted ROP16 $6_{I / I I}$ in order to generate a GRA15 II dominant transformant to explore the pathology of adverse pregnancy and the mechanisms of pathogenesis caused by the atypical strain of Chinese 1 epidemic in China.

Despite of expressing paternal antigens, the human allogenic fetus is histocompatible with the maternal immune system, presenting an immune down-modulation on $\mathrm{CD}^{+} \mathrm{T}$ cells, Th1, and Th17 cells, which contributes to creation of an immuneprivileged environment at the maternal-fetal interface. Previous investigations indicated that microbial endotoxin (LPS) administration to pregnant mice prior to delivery (16.5 day post 


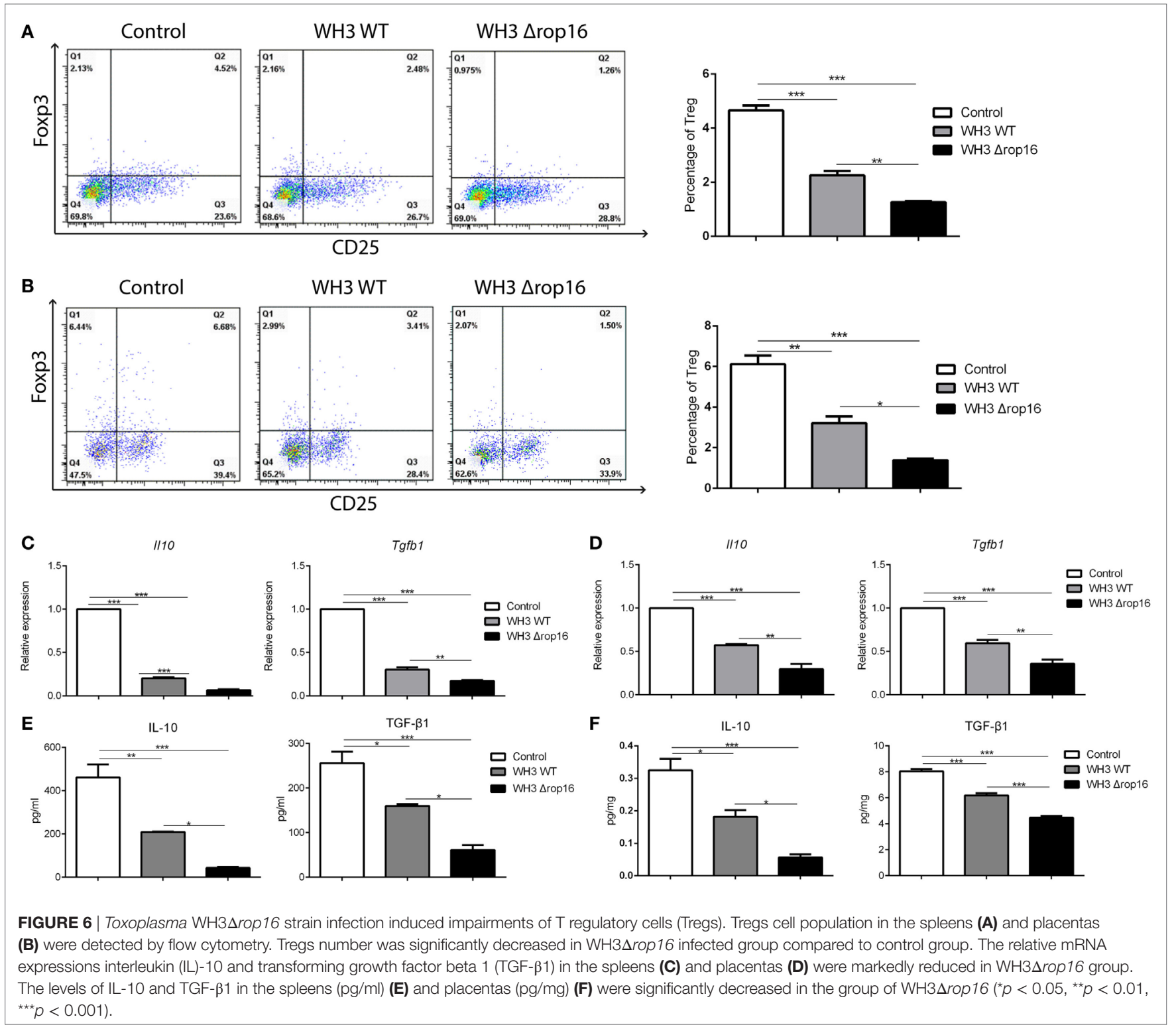

coitum) causes a Tregs and Th17 cells involved imbalance at the maternal-fetal interface and in the spleen, inducing preterm labor (48). However, we found that mice infected with the WH3 3 rop16/gra15II strain at the early stage (seventh day of fertility) presented remarkable manifestations of adverse pregnant results, indicating that the mutant strain infection of Toxoplasma may lead to abnormal pregnant outcomes in which Tregs and Th17 cells are also involved. Various types of immune cells, such as Tregs, play a pivotal role in the maintenance of normal gestation $(11,49-52)$. Our study revealed that the percentage of Tregs and expression of IL-10 and TGF- $\beta 1$ by Tregs as well as M2 cells were significantly diminished in the spleen and placenta tissues of early phase and metaphase of pregnancy of mice infected with the WH3 3 rop $16 /$ gra $15_{I I}$ strain, which is consistent with the previous reports of low expression of IL-10 and TGF- $\beta 1$ cytokines in mice with a high incidence of fetal rejection (53). This result demonstrates that the impairment of Tregs takes place in T. gondiiinfected pregnant mice, particularly in mice infected with the strain of WH3 $\Delta$ rop $16 /$ gra $15_{I I}$.

A growing body of evidence indicates that Th17 cells are involved in infiltrative inflammation in patients with recurrent spontaneous abortions (54). The imbalance of Tregs/Th17 has also been seen in human abortions $(54,55)$. Our previous work revealed that T. gondii type II strain-derived molecule of ToxoGRA15 II is responsible for inducing M1 polarization of RAW264.7 cells via NF- $\kappa \mathrm{B}$ activation $(29,56)$ eliciting host innate immunity and Th1-dominant and Th17-involved inflammatory response, and adverse pregnancy outcomes in mice (data in manuscript). Here, we also noted that expression of Th1 cytokines and IL-17A in splenocytes and placenta tissues was observably elevated in the pregnant animals infected with WH3 3 rop16/gra15 II strain 


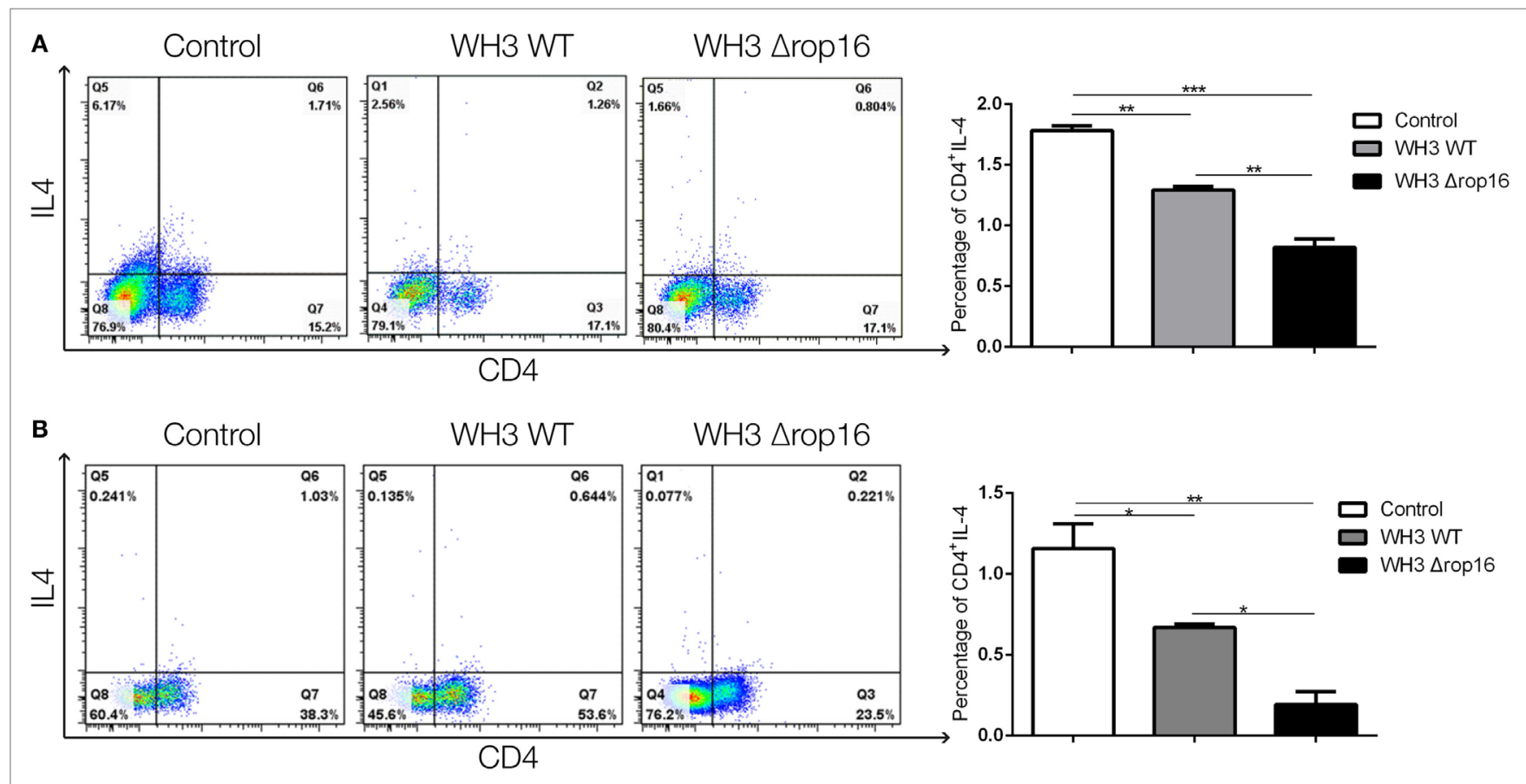

FIGURE 7 | Toxoplasma WH3 $\Delta$ rop16 strain infection downregulated Th2 response of pregnant mice. The expression of IL-4 in WH3 $\Delta$ rop16 group in the spleens (A) and placentas (B) compared to the control group determined with flow cytometry $\left({ }^{\star} p<0.05,{ }^{* *} p<0.01,{ }^{* \star *} p<0.001\right)$.

of type Chinese 1 (Figures 4 and 5), implying a direct involvement of increased Th17 cells in fetal loss. Additional studies are on going to explore the IFN- $\gamma / \mathrm{NK}$-involved mechanism at the maternal-fetal interface in abnormal pregnancies associated with T. gondii infection.

In summary, our data demonstrate that WH3 $\Delta$ rop16 strain with GRA15 II background of T. gondii type Chinese 1 may cause subversion of immune tolerance at the maternal-fetus interface and in systemic immunity, leading to adverse pregnancy outcomes, which is associated with the Th1 and Th17 biased response. This study would provide an explanation for pregnancy failure caused by non/less virulent strains of type II and offer a deep insight into the pathogenesis of abnormal pregnancy caused by strains of T. gondii type Chinese 1 dominating in China.

\section{ETHICS STATEMENT}

The mice were treated in compliance with the Chinese National Institute of Health Guide for the Care and Use of Laboratory Animals. All procedures were followed strictly according to the ethical standards formulated by Institutional Review Board of Anhui Medical University Institute of Biomedicine (permit no: AMU26-081108).

\section{REFERENCES}

1. Sacks GP, Studena K, Sargent K, Redman CW. Normal pregnancy and preeclampsia both produce inflammatory changes in peripheral blood leukocytes akin to those of sepsis. Am J Obstet Gynecol (1998) 179(1):80-6. doi:10.1016/ S0002-9378(98)70254-6

\section{AUTHOR CONTRIBUTIONS}

JS and CW conceived and designed the experiments. CW, WC, QY, and TX performed the experiments. WC, CW, and JS drafted the manuscript. All authors contributed to discussion of the results followed by writing and reviewing the manuscript.

\section{ACKNOWLEDGMENTS}

The pSAG1:CAS9-U6:sgUPRT was gifted by David Sibley at Washington University School of Medicine, USA. The pDHFRTS plasmid was a gift from Honglin Jia in Harbin Veterinary Research Institute of Chinese Academy of Agricultural Sciences, China.

\section{FUNDING}

The work was funded by the National Key R\&D Program of China (No. 2017YFD0500400), the National Science Foundation of China (No. 81471983), the National Basic Research Program of China (No. 2010CB530001), and the Natural Science Foundation of China(NSFC funding NO.81572801).

2. Trowsdale J, Betz AG. Mother's little helpers: mechanisms of maternal-fetal tolerance. Nat Immunol (2006) 7(3):241-6. doi:10.1038/ni1317

3. Saito S, Sakai M, Sasaki Y, Tanebe K, Tsuda H, Michimata T. Quantitative analysis of peripheral blood Th0, Th1, Th2 and the Th1: Th2 cell ratio during normal human pregnancy and preeclampsia. Clin Exp Immunol (1999) 117(3):550-5. doi:10.1046/j.1365-2249.1999.00997.x 
4. Huppertz B, Kadyrov M, Kingdom JC. Apoptosis and its role in the trophoblast. Am J Obstet Gynecol (2006) 195(1):29-39. doi:10.1016/j.ajog.2005. 07.039

5. Asseman C, Mauze S, Leach MW, Coffman RL, Powrie F. An essential role for interleukin 10 in the function of regulatory $\mathrm{T}$ cells that inhibit intestinal inflammation. J Exp Med (1999) 190(7):995-1004. doi:10.1084/jem. 190.7.995

6. Santner-Nanan B, Straubinger K, Hsu P, Parnell G, Tang B, Xu B, et al. Fetalmaternal alignment of regulatory T cells correlates with IL-10 and Bcl-2 upregulation in pregnancy. J Immunol (2013) 191(1):145-53. doi:10.4049/jimmunol. 1203165

7. Zenclussen AC, Gerlof K, Zenclussen ML, Ritschel S, Zambon Bertoja A, Fest S, et al. Regulatory $\mathrm{T}$ cells induce a privileged tolerant microenvironment at the fetal-maternal interface. Eur J Immunol (2006) 36(1):82-94. doi:10.1002/ eji.200535428

8. Maloy KJ, Salaun L, Cahill R, Dougan G, Saunders NJ, Powrie F. $\mathrm{CD} 4+\mathrm{CD} 25+\mathrm{T}(\mathrm{R})$ cells suppress innate immune pathology through cytokine-dependent mechanisms. J Exp Med (2003) 197(1):111-9. doi:10.1084/ jem.20021345

9. Darrasse-Jeze G, Klatzmann D, Charlotte F, Salomon BL, Cohen JL. $\mathrm{CD} 4+\mathrm{CD} 25+$ regulatory/suppressor $\mathrm{T}$ cells prevent allogeneic fetus rejection in mice. Immunol Lett (2006) 102(1):106-9. doi:10.1016/j.imlet.2005. 07.002

10. Lash GE, Otun HA, Innes BA, Kirkley M, De Oliveira L, Searle RF, et al. Interferon-gamma inhibits extravillous trophoblast cell invasion by a mechanism that involves both changes in apoptosis and protease levels. FASEB $J$ (2006) 20(14):2512-8. doi:10.1096/f.06-6616com

11. Piccinni MP, Beloni L, Livi C, Maggi E, Scarselli G, Romagnani S. Defective production of both leukemia inhibitory factor and type 2 T-helper cytokines by decidual T cells in unexplained recurrent abortions. Nat Med (1998) 4(9):1020-4. doi:10.1038/2006

12. Mjosberg J, Berg G, Jenmalm MC, Ernerudh J. FOXP3+ regulatory T cells and Thelper 1, T helper 2 , and T helper 17 cells in human early pregnancy decidua. Biol Reprod (2010) 82(4):698-705. doi:10.1095/biolreprod.109.081208

13. Lin H, Mosmann TR, Guilbert L, Tuntipopipat S, Wegmann TG. Synthesis of T helper 2-type cytokines at the maternal-fetal interface. J Immunol (1993) 151(9):4562-73.

14. Xu C, Mao D, Holers VM, Palanca B, Cheng AM, Molina H. A critical role for murine complement regulator crry in fetomaternal tolerance. Science (2000) 287(5452):498-501. doi:10.1126/science.287.5452.498

15. Montoya JG, Liesenfeld O. Toxoplasmosis. Lancet (2004) 363(9425):1965-76. doi:10.1016/S0140-6736(04)16412-X

16. Wong SY, Remington JS. Toxoplasmosis in pregnancy. Clin Infect Dis (1994) 18(6):853-61; quiz 862. doi:10.1093/clinids/18.6.853

17. Robbins JR, Zeldovich VB, Poukchanski A, Boothroyd JC, Bakardjiev AI. Tissue barriers of the human placenta to infection with Toxoplasma gondii. Infect Immun (2012) 80(1):418-28. doi:10.1128/IAI.05899-11

18. Xu X, He L, Zhang A, Li Q, Hu W, Chen H, et al. Toxoplasma gondii isolate with genotype Chinese 1 triggers trophoblast apoptosis through oxidative stress and mitochondrial dysfunction in mice. Exp Parasitol (2015) 154:51-61. doi:10.1016/j.exppara.2015.04.008

19. Hunter CA, Sibley LD. Modulation of innate immunity by Toxoplasma gondii virulence effectors. Nat Rev Microbiol (2012) 10(11):766-78. doi:10.1038/ nrmicro2858

20. Wang H, Hirsch E. Bacterially-induced preterm labor and regulation of prostaglandin-metabolizing enzyme expression in mice: the role of tolllike receptor 4. Biol Reprod (2003) 69(6):1957-63. doi:10.1095/biolreprod.103. 019620

21. Fu B, Li X, Sun R, Tong X, Ling B, Tian Z, et al. Natural killer cells promote immune tolerance by regulating inflammatory TH17 cells at the human maternal-fetal interface. Proc Natl Acad Sci U S A (2013) 110(3):E231-40. doi:10.1073/pnas.1206322110

22. Zhang H, Hu X, Liu X, Zhang R, Fu Q, Xu X. The Treg/Th17 imbalance in Toxoplasma gondii-infected pregnant mice. Am J Reprod Immunol (2012) 67(2):112-21. doi:10.1111/j.1600-0897.2011.01065.x

23. Lee SK, Kim JY, Lee M, Gilman-Sachs A, Kwak-Kim J. Th17 and regulatory T cells in women with recurrent pregnancy loss. Am J Reprod Immunol (2012) 67(4):311-8. doi:10.1111/j.1600-0897.2012.01116.x
24. Saeij JP, Boyle JP, Coller S, Taylor S, Sibley LD, Brooke-Powell ET, et al. Polymorphic secreted kinases are key virulence factors in toxoplasmosis. Science (2006) 314(5806):1780-3. doi:10.1126/science.1133690

25. Taylor S, Barragan A, Su C, Fux B, Fentress SJ, Tang K, et al. A secreted serine-threonine kinase determines virulence in the eukaryotic pathogen Toxoplasma gondii. Science (2006) 314(5806):1776-80. doi:10.1126/science. 1133643

26. Saeij JP, Coller S, Boyle JP, Jerome ME, White MW, Boothroyd JC. Toxoplasma co-opts host gene expression by injection of a polymorphic kinase homologue. Nature (2007) 445(7125):324-7. doi:10.1038/nature05395

27. Reese ML, Zeiner GM, Saeij JP, Boothroyd JC, Boyle JP. Polymorphic family of injected pseudokinases is paramount in Toxoplasma virulence. Proc Natl Acad Sci U S A (2011) 108(23):9625-30. doi:10.1073/pnas.1015980108

28. Rosowski EE, Lu D, Julien L, Rodda L, Gaiser RA, Jensen KD, et al. Strainspecific activation of the NF-kappaB pathway by GRA15, a novel Toxoplasma gondii dense granule protein. J Exp Med (2011) 208(1):195-212. doi:10.1084/ jem.20100717

29. Xie Y, Wen H, Yan K, Wang S, Wang X, Chen J, et al. Toxoplasma gondii GRA15II effector-induced M1 cells ameliorate liver fibrosis in mice infected with Schistosomiasis japonica. Cell Mol Immunol (2016) 15(2):120-34. doi:10.1038/cmi.2016.21

30. Jensen KD, Wang Y, Wojno ED, Shastri AJ, Hu K, Cornel L, et al. Toxoplasma polymorphic effectors determine macrophage polarization and intestinal inflammation. Cell Host Microbe (2011) 9(6):472-83. doi:10.1016/j.chom. 2011.04.015

31. Loke P, Allison JP. PD-L1 and PD-L2 are differentially regulated by Th1 and Th2 cells. Proc Natl Acad Sci U S A (2003) 100(9):5336-41. doi:10.1073/pnas. 0931259100

32. Melo MB, Jensen KD, Saeij JP. Toxoplasma gondii effectors are master regulators of the inflammatory response. Trends Parasitol (2011) 27(11):487-95. doi:10.1016/j.pt.2011.08.001

33. Cheng W, Liu F, Li M, Hu X, Chen H, Pappoe F, et al. Variation detection based on next-generation sequencing of type Chinese 1 strains of Toxoplasma gondii with different virulence from China. BMC Genomics (2015) 16:888. doi:10.1186/s12864-015-2106-z

34. Cai Y, Chen H, Mo X, Tang Y, Xu X, Zhang A, et al. Toxoplasma gondii inhibits apoptosis via a novel STAT3-miR-17-92-Bim pathway in macrophages. Cell Signal (2014) 26(6):1204-12. doi:10.1016/j.cellsig.2014.02.013

35. Shen B, Brown KM, Lee TD, Sibley LD. Efficient gene disruption in diverse strains of Toxoplasma gondii using CRISPR/CAS9. MBio (2014) 5(3): e01114-01114. doi:10.1128/mBio.01114-14

36. Ding AH, Nathan CF, Stuehr DJ. Release of reactive nitrogen intermediates and reactive oxygen intermediates from mouse peritoneal macrophages. Comparison of activating cytokines and evidence for independent production. J Immunol (1988) 141(7):2407-12.

37. Remington JS, McLeod R, Desmonts G. Toxoplasmosis. 4th ed. In: Remington JS, Klein JO, editors. Infectious Diseases of the Fetus and Newborn Infant. Philadelphia: WB Saunders (1995). p. 140-267.

38. Dunn D, Wallon M, Peyron F, Petersen E, Peckham C, Gilbert R. Mother-tochild transmission of toxoplasmosis: risk estimates for clinical counselling. Lancet (1999) 353(9167):1829-33. doi:10.1016/S0140-6736(98)08220-8

39. Vargas-Villavicencio JA, Cedillo-Pelaez C, Rico-Torres CP, Besne-Merida A, Garcia-Vazquez F, Saldana JI, et al. Mouse model of congenital infection with a non-virulent Toxoplasma gondii strain: vertical transmission, "sterile" fetal damage, or both? Exp Parasitol (2016) 166:116-23. doi:10.1016/j.exppara. 2016.04.002

40. Senegas A, Villard O, Neuville A, Marcellin L, Pfaff AW, Steinmetz T, et al. Toxoplasma gondii-induced foetal resorption in mice involves interferongamma-induced apoptosis and spiral artery dilation at the maternofoetal interface. Int J Parasitol (2009) 39(4):481-7. doi:10.1016/j.ijpara.2008.08.009

41. Pfaff AW, Abou-Bacar A, Letscher-Bru V, Villard O, Senegas A, Mousli M, et al Cellular and molecular physiopathology of congenital toxoplasmosis: the dual role of IFN-gamma. Parasitology (2007) 134(Pt 13):1895-902. doi:10.1017/ S0031182007000200

42. Rico-Torres CP, Vargas-Villavicencio JA, Correa D. Is Toxoplasma gondii type related to clinical outcome in human congenital infection? Systematic and critical review. Eur J Clin Microbiol Infect Dis (2016) 35(7):1079-88. doi:10.1007/ s10096-016-2656-2 
43. Howe DK, Sibley LD. Toxoplasma gondii comprises three clonal lineages: correlation of parasite genotype with human disease. J Infect Dis (1995) 172(6):1561-6. doi:10.1093/infdis/172.6.1561

44. Sibley LD, Boothroyd JC. Virulent strains of Toxoplasma gondii comprise a single clonal lineage. Nature (1992) 359(6390):82-5. doi:10.1038/359082a0

45. Murray PJ. Macrophages as a battleground for Toxoplasma pathogenesis. Cell Host Microbe (2011) 9(6):445-7. doi:10.1016/j.chom.2011.05.010

46. Yamamoto M, Standley DM, Takashima S, Saiga H, Okuyama M, Kayama H, et al. A single polymorphic amino acid on Toxoplasma gondii kinase ROP16 determines the direct and strain-specific activation of Stat3. J Exp Med (2009) 206(12):2747-60. doi:10.1084/jem.20091703

47. Shen B, Brown K, Long S, Sibley LD. Chapter 6. Development of CRISPR/ Cas9 for efficient genome editing in Toxoplasma gondii. In: Reeves A, editor. In Vitro Mutagenesis Methods and Protocols. Warrenville, IL: Coskata, Inc. (2017) 79-106.

48. Arenas-Hernandez M, Romero R, St Louis D, Hassan SS, Kaye EB, GomezLopez N. An imbalance between innate and adaptive immune cells at the maternal-fetal interface occurs prior to endotoxin-induced preterm birth. Cell Mol Immunol (2016) 13(4):462-73. doi:10.1038/cmi.2015.22

49. Somerset DA, Zheng Y, Kilby MD, Sansom DM, Drayson MT. Normal human pregnancy is associated with an elevation in the immune suppressive CD25+ CD4+ regulatory T-cell subset. Immunology (2004) 112(1):38-43. doi:10.1111/j.1365-2567.2004.01869.x

50. Tilburgs T, Scherjon SA, van der Mast BJ, Haasnoot GW, Versteeg VDV-MM, Roelen DL, et al. Fetal-maternal HLA-C mismatch is associated with decidual $\mathrm{T}$ cell activation and induction of functional $\mathrm{T}$ regulatory cells. J Reprod Immunol (2009) 82(2):148-57. doi:10.1016/j.jri.2009.05.003

51. Tilburgs T, Roelen DL, van der Mast BJ, de Groot-Swings GM, Kleijburg C, Scherjon SA, et al. Evidence for a selective migration of fetus-specific $\mathrm{CD} 4+\mathrm{CD} 25$ bright regulatory $\mathrm{T}$ cells from the peripheral blood to the decidua in human pregnancy. J Immunol (2008) 180(8):5737-45. doi:10.4049/jimmunol. 180.8.5737
52. Quinn KH, Lacoursiere DY, Cui L, Bui J, Parast MM. The unique pathophysiology of early-onset severe preeclampsia: role of decidual T regulatory cells. J Reprod Immunol (2011) 91(1-2):76-82. doi:10.1016/j.jri.2011.05.006

53. Blois S, Tometten M, Kandil J, Hagen E, Klapp BF, Margni RA, et al. Intercellular adhesion molecule-1/LFA-1 cross talk is a proximate mediator capable of disrupting immune integration and tolerance mechanism at the fetomaternal interface in murine pregnancies. J Immunol (2005) 174(4):1820-9. doi:10.4049/jimmunol.174.4.1820

54. Wang WJ, Hao CF, Yi L, Yin GJ, Bao SH, Qiu LH, et al. Increased prevalence of Thelper 17 (Th17) cells in peripheral blood and decidua in unexplained recurrent spontaneous abortion patients. J Reprod Immunol (2010) 84(2):164-70. doi:10.1016/j.jri.2009.12.003

55. Liu YS, Wu L, Tong XH, Wu LM, He GP, Zhou GX, et al. Study on the relationship between Th17 cells and unexplained recurrent spontaneous abortion. Am J Reprod Immunol (2011) 65(5):503-11. doi:10.1111/j.1600-0897. 2010.00921.x

56. Li Y, Poppoe F, Chen J, Yu L, Deng F, Luo Q, et al. Macrophages polarized by expression of ToxoGRA15II inhibit growth of hepatic carcinoma. Front Immunol (2017) 8:137. doi:10.3389/fimmu.2017.00137

Conflict of Interest Statement: The authors declare that the research was conducted in the absence of any commercial or financial relationships that could be construed as a potential conflict of interest.

Copyright $\odot 2018$ Wang, Cheng, Yu, Xing, Chen, Liu, Yu, Du, Luo, Shen and Xu. This is an open-access article distributed under the terms of the Creative Commons Attribution License (CC BY). The use, distribution or reproduction in other forums is permitted, provided the original author(s) and the copyright owner are credited and that the original publication in this journal is cited, in accordance with accepted academic practice. No use, distribution or reproduction is permitted which does not comply with these terms. 